\title{
Determinants of Work Relation Perception: Organizational Culture in Egyptian Workplaces
}

\author{
Mohamed Taha Mohamed ${ }^{1}$ \\ ${ }^{1}$ Psychology Department, Ain Shams University, Cairo, Egypt \\ Correspondence: Mohamed Taha Mohamed, Psychology Department, College of Arts, Ain Shams University, \\ Cairo, Egypt. Tel: 20-100-333-0291. E-mail: Mohamed_taha@art.asu.edu.eg
}

Received: October 31, 2013

Accepted: November 11, $2013 \quad$ Online Published: November 22, 2013

doi:10.5539/ijps.v5n4p86

URL: http://dx.doi.org/10.5539/ijps.v5n4p86

\begin{abstract}
This study aimed at investigating different types of organizational cultures common in Egyptian workplaces and how they might be influenced by the type of ownership (governmental, public, or private), the region in which the organization exists (Cairo, North Egypt, or South Egypt), and the organization size (large vs. small). Organizational cultures were divided, according to the Competing Values Model proposed Cameron and Quinn (1999/2006), into four types: Market, Hierarchy, Adhocracy, and Clan cultures. Organizational cultures were evaluated by developing an Arabic/Egyptian standardized version of the Organizational Climate Measure (OCM) prepared originally by Patterson and his colleagues (Patterson et al. 2005). OCM was based on the Competing Values Model and was designed to assess the four basic dimensions of the model, and it went further to define specific components (which ranged from 2 to 6) for every dimension, with 4 to 6 items for each component. In the OCM, the Clan culture was renamed Human Relations culture, which includes 6 dimensions, and Hierarchy culture became Internal Process culture and included 2 components. Similarly, Adhocracy culture was renamed Open System culture with 3 components, and Market culture was renamed Rational Goal culture with 6 components. A sample of 158 employees working in different professions participated in the study. Their ages ranged between 19 to 62 years old and their mean age was 34.94 years $(\mathrm{SD}=10.61) .82(52 \%)$ were males ad 76 (48\%) were females. A $3 \times 3 \times 2$ MANOVA of the data was conducted. Results indicated that private organizations got higher scores on Human Relations, Open System, and Rational Goal cultures than governmental organizations (but not necessarily the public ones). On the other hand, organizations in North Egypt and Cairo got higher scores than their counterparts in South Egypt in Human Relations (integration and training), Open System (innovation) and most components of Rational Goal culture. However, South Egypt organizations showed higher level of Internal Process (familiarization and tradition) than the organizations in Cairo and North Egypt. As for Organization size, it has in general a limited effect on organizational culture but large organizations showed significantly higher level of Internal Process (familiarization) and Rational Goal (efficiency) cultures than small ones, which showed higher level of Open System (innovation) culture. The patterns of interactions showed that public organizations in the north can have higher level of Open System culture (innovation) than their private and governmental counterparts. Also, Human Relations culture (especially training) can be important in small, family-owned organizations in South and North Egypt in comparison to Cairo. Moreover, although private organizations tend to give employees more independence and responsibility, the large ones tend to be more restrictive and formal than public and governmental ones, especially in Cairo (where they usually have their central headquarters). Counter to the common belief, Rational Goal culture (work quality and pressure to work) were higher in governmental organizations in South Egypt than private and public ones because of the limited resources available to the private section in this region.
\end{abstract}

Keywords: organizational culture, workplaces in Egypt, work relations, Organizational Climate Measure (OCM)

\section{Introduction}

Since late 1970s and early 1980s, the concept of organizational culture has played a significant role in industrial/organizational (I/O) psychology. A substantial literature on organizational psychology and management shows it is related to a diverse set of issues and variables in work environment such as organizational performance (Bulach, Lunenburg, \& Potter, 2012; Kotter, 2012; Lunenburg, 2011; Patterson, 
Warr, \& West, 2004; Peters \& Waterman, 2006; Wilderom, Glunk, \& Maslowski, 2000), job satisfaction (Arnold \& Spell, 2006; Mansoor \& Tayib, 2010; McKinnon, Harrison, Chow, \& Wu, 2003; Sabri, Ilyas, Amjad, 2011), leadership (Change \& Lee, 2007; Ogbonna \& Harris, 2000; Schein, 1992), and job turnover (Edgington \& Bruce, 2006; Islam, Khan, Aamir, \& Ahmad, 2012; Kitts \& Trowbridge, 2007; Nelson, 2011). Although I/O psychology has been relatively well-established in Egypt since the 1950s, very little work was done about organizational culture in workplaces in Egypt or in other Arab countries. The Current study aims at investigating different factors that might affect organizational culture; specifically the type of ownership, regional culture, and organizational size.

\subsection{Organizational Culture}

A basic assumption in studying organizational culture is that every institution has its own personality. This style of personality affects different aspects of life and work in workplaces such as the interactions among their members, actual (rather than formal) hierarchical structures, patterns of leadership, and balances between different wings of power in the organization. In short, organizational culture reflects unwritten rules and style of relationships in the organization, as well as formal rules and structures. Workplaces, accordingly, can be considered social, living organisms that go through different stages of development, and every stage has its own values, assumptions, heroes, and even logos. These aspects, thus, include both symbolic and concrete features of life in the organization. Moreover, it is important to emphasize that organizational culture is a cognitive phenomenon that reflects reality in the organization as perceived by its members, rather than as it is. Organizational culture is one of the fronts of interface between cognitive psychology and industrial/organizational psychology, which is based on the assumption that individuals in the same organizations develop shared mental models and internal representations of the acts and events in their organizations (Hodgkinson, 2003). These models and representations basically give acts and events in the organizations meaning and put them in context.

Organizational culture plays an important role in providing shared patterns of cognitive interpretations and perceptions of the work environment, which affect how individuals feel about this environment. It is also instrumental for maintaining boundaries and determining acceptable and unacceptable behavior. In short, organizational culture provides a sense of identity to the members of the organization. Accordingly, it can be seen as a socialization process that helps newcomers to understand "how things are done around here" in order to make them fit better within the organization. Clampitt (2001) specifies three major agents of this socialization process: priests, storytelling, and gossips. In this conceptualization, priests' role is to maintain and bless the values of the organization, while storytellers basically watch over these values. Gossips, on the other hand, are considered the key transmitters of the culture. Thus, organizational culture is a dynamic process that is affected by the organization's stage of development as each stage of the organization's life requires different culture. According to Pettigrew (1979; Pettigrew, Woodman, \& Cameron, 2001), organizations in their early (embryonic) stage of development have cohesive cultures that reflect the founders' values and visions. These cultures tend to become less and less cohesive as organizations grow and mature. Eventually, culture becomes a defense in the final (decline) stage of the organization's development. Organizations' success can be accounted for, to a large extent, by their flexibility and ability to change culture to align with the organization's stage of development. In Peter and Waterman's (2006) study, companies that were successful in the 1970s were no longer successful in the 1990s because they could not adapt to market challenges. Of course, emphasizing the existence of organizational culture does not guarantee this culture's positive nature as it can be positive in healthy and successful organizations, or negative in corrupted and failed ones (Schneider,1987). Issues such as the culture focus (whether it is relations-oriented or instrumentality-oriented) and its expected end-users (whether it is workers' culture focusing on human relations and or management's culture focusing on work relations) are controversial ones that imposes moral challenges to organizational psychologists (Bagrain, 2001).

Historically, the concept of organizational culture can be traced back to the "human relations" approach, which was dominant in 1940s and emphasized a qualitative, informal, and interpersonal approach to management. However, the focus shifted in the 1960s and the 1970s to the more quantitative "rational system" approach, which emphasized measurable aspects of work conditions and workers' attitudes. This approach was referred to as measuring "organizational climate" or behavioral manifestations of social interactions within the organizations. The term "organizational culture" appeared in late 1970s and early 1980s. It represented a return to the qualitative approach to understanding work relations, and focused on values and assumptions dominant in different workplaces (Baker, 2002). The emergence of the "organizational culture" concept in the Western management and social science literature in 1980s was, in part, a response to the Japanese challenge to the American industry. Trying to understand the reasons behind success of the Japanese organizations, experts 
started to examine the feudal-military traditions in the Japanese society and how it is related to work relations and interactions in major Japanese corporations (Ouchi, 1981; Pascale \& Athos, 1982). Later, the organizational climate and organizational culture concepts were used interchangeably but climate is basically understood as the surface manifestations of culture (Patterson et al, 2005; Schein, 1992). That is, climate is taken to refer to the behavioral, directly observable aspects of workplaces while culture is considered the deeper level of values, assumptions, and other inferred aspects of them.

Given this conceptualization of organizational culture as a dynamic phenomenon with different levels, the current study adopts Schein's definition of the organizational culture as "a pattern of shared basic assumptions that a group leaned as it solved its problems of external adaptations and internal integration, that has worked well enough to be considered valid and, therefore, to be taught to new members as the correct way to perceive, think, and feel in relations to these problems" (Schein, 1992, p. 12). This definition emphasizes the dynamic, functional nature of the organizational culture as it implies that organizational culture is (1) a cognitive phenomenon that is based on building a shared mental model, (2) a phenomenon that is developed through the organizational experience of internal and external challenges, and (3) a socialization process that creates a sense of identity. In Schein's conceptualization, there are three layers of organizational culture. The first is the artifacts in the organization. This layer includes concrete aspects of the culture that can be seen and heard such as the logos, physical settings, dress code, and communication styles. The second layer is the values of the organization and includes abstract aspects of the organization that reflect its current mission, goals, strategies, and plans for the future. The third layer of the organizational culture, according to Schein, is the core assumptions of the organization. These assumptions are a set of invisible, preconscious ones that developed over the course of the organization's development. They include perceptions, feelings, and interpretations of human nature, work relations, and nature of work. In fairly established organizations, these assumptions are taken for granted and supported by major themes, myths, and traditions in these organizations.

To understand a culture prevalent in particular organization, some researchers (e.g., Cameron \& Quinn, 2006) tried to specify the basic dimensions of cultures. In this regard, two basic dimensions were recognized. The first one is the external-internal dimension which distinguishes between organizations based on whether they emphasize external orientation, differentiation, and competition or internal orientation, integration, and unity. The second recognized dimension, on the other hand, is control-flexibility dimension which distinguishes between organizations based on whether they emphasize stability and order, or discretion and dynamism. The interaction between these two dimensions resulted in four major types of organizational culture (see Table 1): Market, Hierarchy, Adhocracy, and Clan. Together, they are known as the Competing Values Framework, developed by Cameron and Quinn (2006).

Table 1. Four types of organizational culture in the competing values framework

\begin{tabular}{lll}
\hline Basic Dimensions & External & Internal \\
\hline Control & Market & Hierarchy \\
Flexibility & Adhocracy & Clan \\
\hline
\end{tabular}

According to the competing values framework, the four organizational cultures can be characterized as follows:

1) Market organizational culture is characterized by being results-oriented and the dominant values in organization with this culture are winning, competitiveness, and productivity.

2) Hierarchy organizational culture is characterized by being structure-based culture, which emphasizes formal rules and policies, stability, and predictability.

3) Adhocracy organizational culture is characterized by being vision-based culture, which supports the values of creativity, risk taking, and work under the stress of uncertainty and ambiguity.

4) Clan organizational culture is characterized by being based on teamwork and concern for people, where human relations and employee development are priorities.

Of course, only a few organizations can be characterized by having a certain culture that is prevalent throughout the whole organization. Rather, most organizations have some aspects of all of these cultures with different weights and levels of emphasis. This leads to a more to more complicated and realistic picture of cultural complexity (Denison et al. 1995) in organizations, where different divisions and departments develop their own 
different cultures. A major challenge to management in this case is the orchestration of these different and competing cultures to get the best possible performance.

\subsection{Studying Organization Culture in Egyptian Context}

In 1990s, Egypt witnessed a substantial transformation toward privatization and market economy. This came as part of global recent changes in this era that were launched by the end of the Cold War and the collapse of Berlin wall. A basic aspect of these changes is that they supported a shift in many Third World countries toward the Western model of liberal economy as the ultimate model of human welfare, according to some researchers (e.g., Fokoyama, 1992), even though this shift was not necessarily accompanied by the western values of democracy and transparency. This shift in Egypt was induced by the recommendations of international financial institutions (namely World Bank and International Monetary Fund) and the special ties Egypt has with the U.S. since late 1970s. The acceleration of the transformation towards a liberal economy was formalized in 1991 when Egypt concluded Economic Reform and Structural Adjustment Program (ERSAP) agreements with the World Bank and International Monetary Fund (Solidarity Center, 2010). This new economic orientation elicited both academic criticism and social protest. Academic critiques argued that economic performance of different organizations is related to successful management practices regardless of the economic system, and they usually cite the economic growth in China to prove their point. On the other hand, social protests became a phenomenon in the last 10 years in Egypt. According to some estimations, Egypt witnessed more than 1,900 strikes, protests, and sits-ins between 2004 and 2008, and over 1.7 Million workers were engaged in such actions (Solidarity Center, 2010). Moreover, there were approximately 1000 industrial protests in 2009, and 300 labor strikes in the first half of 2010 (Ottaway \& Hamzawy, 2011). These protests and demonstrations were basically against corruption, privatization, and the perceived social injustice resulting from them. These protests continued and contributed significantly in the major uprising that led to the Egyptian revolution in 2011. Given this turning point in Egyptian politics and related changes in work relations, studying organizational culture in different Egyptian workplaces can be useful for understanding the effect of recent changes of privatization on work relations, general climate, and management strategies. Moreover, studying organization culture in Egypt might provide cross cultural validation to the concept and show how its manifestations and determinants might differ in a non-western cultural setting with different historical and social background.

However, studying organizational culture in Egyptian workplaces was very limited to a single study (to the best of the author's knowledge). In an ethnographic study using participant observation method to study organizational culture in two government-owned textile firms, Shehata (2003) found that work relations and organizational climate in these two firms were characterized by authoritarianism and hierarchism. Moreover, Shehata argued that these characteristics describe the general relationship with authority in Egyptian society as a whole, and are not limited to these two firms. Although Shehata's (2003) study was a pioneer in the field, it was not guided by any theoretical model of organizational culture, and findings were based on subjective analysis of anecdotal evidence. The current study tries to investigate organizational culture in a much wider range of public and private Egyptian organizations, using more rigorous methods of data collection and analysis.

\subsection{Current Research}

The current study is an exploratory study that tries to understand different aspects of the four types of the organizational culture, as specified in the competing values framework (Cameron \& Quinn, 2006) in different Egyptian workplaces. In particular, while there is a fairly established literature studying how organizational culture affects or correlates with work related variables such as organizational performance, job satisfaction, turnover intentions, leadership style, the current study investigates how economic and demographic factors such as type of ownership, location, and size of workplaces might affect or correlate with organizational culture.

Studying the effect of the type of ownership on organizational culture can be attributed to the fact that there is a contradictory literature documenting organizational culture differences between private and public workplaces. For example, while Ferreira and her team found that private companies in Brazil have more open, cooperative, professional, and less rigid culture than their public counterparts (Ferreira, Assmar, Estol, Chagas, \& Cisne, 2004), Owusu (2005) found that performance of Ghanaian organizations in general was related to management practices, rather than being privately or publicly owned.

This is an important factor to consider in Egypt, given the fact that Egypt has three types of ownership: Private, governmental, and public. While private and governmental organizations are equivalent to their private and public counterparts, respectively, in the West and in Western studies, public organizations in Egypt are organizations that are owned and supervised by the state (like governmental agencies) but managed by individuals or teams who are given more flexibility and wider authorities. Usually, management in these 
organizations is fairly independent of state regulations and applies more recent styles of management. Considering Egyptian public organizations provides a chance to study how differences in management styles, though with the same owner (the government), might have different effect on organizational culture.

On the other hand, studying organizational culture in different areas in Egypt (Cairo, North Egypt, and South Egypt) should shed light on the relationship between types of relations in certain culture (face-to-face vs. contractual relations) and work, organizational relations in this culture. Given the general distinction between life styles and nature of relationships in rural versus urban societies (for a review, see Bonner, 1998), it might be reasonable to assume that people living in urban areas, where life style is more complicated and faster, should have different organizational culture in their workplaces from those who live in rural areas. Again, Egypt has three major distinct areas: Cairo, North Egypt, and South Egypt. Cairo, which is the capital of the country and a cosmopolitan city with more than 16 Million individuals living in it, is usually considered as whole an urban area North Egypt and South Egypt, on the other hand, are areas with rural and urban sections. However, the majority of the sections are rural ones. An important difference between them, though, is that North Egypt area is much less conservative and relatively highly developed (with better infrastructure and higher rates of education) in comparison to the traditionally neglected South Egypt area.

Finally, it was assumed that there might be organizational culture differences between organizations with different sizes. Again, the rationale here is that relatively small organizations have personal, face-to-face relations that might create organizational cultures that is different from those in big ones, where formal, impersonal relations prevail.

\section{Method}

\subsection{Sample}

158 employees, with diverse qualifications and working at different professions, participated in this study. They were chosen randomly and belonged to a wide range of ages, income, years of experience, and different types of organizations. Out of them, $82(51.9 \%)$ participants were males and $76(48.1 \%)$ participants were females. Their ages ranged between 19 years to 62 years, and their mean age was 34.94 years old $(\mathrm{SD}=10.61)$. They belonged mostly to the average and below average income level as their monthly income ranged between 100 to 1200 Egyptian Pounds per month, and their mean income was 446.78 pounds $(\mathrm{SD}=242.36)$. These participants came from the three main regions in Egypt. Accordingly, 73 participants were from Cairo, 41 participants were from North Egypt, and 41 participants were from South Egypt. 53 participants in the sample were working for private organizations, 15 participants were working in public organizations, and 78 participants were working in governmental organizations. These organizations differed in sized as 82 participants in the sample were working in large organizations, 75 participants were working in small ones. Defining large and small organizations was based on the criterion that an organization with less than 100 employees is a small organization, while one with more than 100 employees can be considered a large one.

\subsection{Instruments}

An Egyptian/Arabic version of the Organizational Climate Measure was used in the current study. The original version was prepared by Patterson and his colleagues (Patterson et al. 2005). The measure is a multidimensional instrument, which is theoretically grounded and empirically validated. It is based explicitly on the four types of organizational culture derived from the competing values framework, as outlined above. It basically evaluates the organizational climate as the surface, directly observable level of organizational culture, which reflects the basic, deeper level of values and assumptions in the organization. Accordingly, it addresses four basic dimensions of organizational culture that correspond to the four types specified by the competing values framework, developed by Cameron and Quinn (2006). These dimensions are Human Relations (Clan culture), Internal Processes (Hierarchy culture), Open Systems (Adhocracy culture), and Rational Goal (Market culture). Patterson and his colleagues, even, went further to specify the component scales of each of the previously mentioned dimensions. Accordingly, the Human Relations dimension includes six components, which are autonomy, integration, involvement, supervisory support, training, and welfare. On the other hand, the Internal Processes dimension includes two components, which are formalization and tradition. The open Systems dimension includes three dimensions, which are innovation and flexibility, outward focus, and reflexivity. Finally, the Rational Goal dimension includes six components, which are clarity of organizational goals, efficiency, effort, performance feedback, pressure to produce, and quality. Every one of these components (scales) was represented with a set of statements, which ranged from 4 to 6 statements (for a description of these components and the number of statements representing each of them, see Table 2). Participants evaluate each statement (item) using a 4-point Likert scale, where 1 corresponds to "definitely false" and 4 corresponds to 
"definitely true". Participants circled the numbers that most closely matched their agreement with each statement. Thus, in its final form, the Organizational Climate Measure consists of 82 statements divided into 17 scales, which are in turn divided into the four major dimensions or quadrants comprising the competing values framework.

A major advantage of the Organizational Climate Measure is that it avoids general evaluation or total score of organizational culture. Rather, it provides detailed description of organizational culture and the details of their components. The measure can be used as a whole or can be used to assess one or more of these dimensions in detail. Accordingly, it can provide a more realistic evaluation of different dimensions, based on an explicit theoretical background.

The original version of the Original Organizational Climate Measure was validated using a large sample of 6869 employees drawn from 55 organizations with different sizes in the U.K. The details of the validation process were described in detail by Patterson and his colleagues (Patterson et al. 2005). Cronbach's alpha for the 17 scales ranged from .67 to .91. Exploratory and confirmatory factor analyses were conducted on the data and supported the hypothesized factorial structure. Concurrent validity of the Organizational Climate Measure was proven through significant correlations between the 17 scales in the measure and data about similar variables derived from interviews with the employees and management.

In order to prepare an Egyptian/Arabic version of the Organizational Climate Measure, the measure was translated into simple, standard Arabic. Two bilingual experts reviewed the translation, which resulted in correcting and modifying few items. A bilingual expert who has no experience with the original measure translated the primary Egyptian/Arabic version of the measure back into English. This translation resulted in a version that is close to the original one, and gave assurance that the Egyptian/Arabic version of the measure can be trusted as equivalent to the original one.

Table 2. Description of the component scales constituting the four major dimensions of the organizational climate measure and the number of items representing each of them

\begin{tabular}{|c|c|c|}
\hline Component Scales & Definition & $\begin{array}{l}\text { Number of } \\
\text { statements }\end{array}$ \\
\hline Autonomy & Extent of independence and responsibility employees get during their work. & 5 \\
\hline Integration & Extent of cooperation between sections and departments in the organization. & 5 \\
\hline Involvement & Extent of influence employees might have on decision making process. & 6 \\
\hline Supervisory Support & Extent of support and guidance employees get from their supervisors. & 5 \\
\hline Training & Extent to which the organization cares to develop employees' skills. & 4 \\
\hline Welfare & Extent to which the organization cares about the employees' interests. & 4 \\
\hline Human Relations (Clan Culture) & & 29 \\
\hline Formalization & Emphasizing formal rules and procedures in the organization. & 5 \\
\hline Tradition & $\begin{array}{l}\text { Emphasizing highly established ways of doing business instead of trying new } \\
\text { ones. }\end{array}$ & 4 \\
\hline Internal Process (Hierarchy Culture) & & 9 \\
\hline Innovation \& Flexibility & Emphasizing new approaches to doing business & 6 \\
\hline Outward Focus & Responsiveness to the customers' needs and to the challenges in the market. & 5 \\
\hline Reflexivity & $\begin{array}{l}\text { Reviewing and reflecting upon the organization's directions, strategies, and } \\
\text { procedures. }\end{array}$ & 5 \\
\hline Open Systems (Adhocracy Culture) & & 16 \\
\hline Clarity of Goals & Clear defining of organization's goals. & 5 \\
\hline Efficiency & Extent to which efficiency and productivity are emphasized in the organization. & 4 \\
\hline Effort & Extent to which employees work hard to achieve the organization's goals & 5 \\
\hline Performance Feedback & $\begin{array}{l}\text { Extent and usefulness of evaluation and feedback employees get from their } \\
\text { supervisors }\end{array}$ & 5 \\
\hline
\end{tabular}




\begin{tabular}{ll}
\hline $\begin{array}{l}\text { Pressure to Produce } \\
\text { Euality }\end{array}$ & Expht of pressure on the employees to organizational goals. \\
Rational Goal (Market Culture) &
\end{tabular}

The Egyptian/Arabic version of the Organizational Climate Measure was validated using a sample of 64 employees working in two large manufacturing companies in Cairo. Their ages ranged from 24 to 58 years (average $=41.19, \mathrm{SD}=8.97$ ). Out of this standardization sample, 28 of the participants were males and 36 of them were females. To study the reliability of the measure, split half correlations and Cronbach's alphas of the 17 scales and the four dimensions in the measure were calculated (see Table 2). The split half correlations of the scales were relatively high, and ranged from .503 to .852 , and the Cronbach's alphas ranged from .694 to .889 . Moreover, inter-item correlations between items' scores and the related scale were high. One the other hand, the correlations between each of the four dimensions and the scales that comprise them were calculated and found to be high (see Table 3).

Table 3. Reliability coefficients and inter-item correlations for 17 scales and 4 dimensions in the egyptian/arabic version of the organizational climate measure

\begin{tabular}{lccc}
\hline Scales & $\begin{array}{l}\text { Split half } \\
\text { Correlations }\end{array}$ & $\begin{array}{l}\text { Cronabach's } \\
\text { Alpha }\end{array}$ & $\begin{array}{l}\text { Range of part-whole correlations between } \\
\text { items and scales and between scales and the } \\
\text { major dimensions }\end{array}$ \\
\hline Autonomy & .529 & .694 & $.432-.657$ \\
Integrations & .704 & .709 & $.489-.670$ \\
Involvement & .724 & .837 & $.583-.747$ \\
Support & .783 & .863 & $.650-.822$ \\
Training & .748 & .850 & $.589-.817$ \\
Welfare & .837 & .889 & $.749-.830$ \\
Human Relations & .768 & .886 & $. \mathbf{4 5 7}-. \mathbf{8 6 6 *}$ \\
Formalization & .600 & .734 & $.545-.643$ \\
Tradition & .439 & .759 & $.533-.767$ \\
Internal Process & .595 & .701 & $. \mathbf{7 2 3}-. \mathbf{7 5 8 *}$ \\
Innovation & .798 & .847 & $.613-.790$ \\
Outward Focus & .640 & .814 & $.580-.707$ \\
Reflexivity & .608 & .824 & $.620-.770$ \\
Open Systems & .836 & .874 & $\mathbf{. 8 5 7}-. \mathbf{9 0 1 *}$ \\
Clarity of Goals & .745 & .819 & $.617-.737$ \\
Efficiency & .677 & .786 & $.478-.810$ \\
Effort & .778 & .861 & $.622-.826$ \\
Feedback & .636 & .816 & $.532-.744$ \\
Pressure & .630 & .757 & $.538-.672$ \\
Quality & .503 & .739 & $.510-.696$ \\
Rational Goal & .852 & $\mathbf{. 4 7 9}-. \mathbf{8 1 2 *}$ \\
\hline
\end{tabular}

*Ranges of correlations between dimensions and the scales that comprise them.

Two criteria were used as to establish the validity of the Egyptian/Arabic Organizational Climate Measure. These criteria were organizational performance and Job satisfaction. Depending on the fairly established literature (e.g., Patterson et al. 2004; Peters \& Waterman, 2006; Wilderom et al. 2000), indicating that organizational culture in successful organizations is different from its counterpart in the failed ones, it was 
reasoned that if the Egyptian version of the measure can detect the differences between organizational cultures in successful and unsuccessful organizations, this can be taken as a support to the validity of this version. In this regard, data showed that the four dimensions of organizational culture in the Egyptian version of the measure were different in successful organizations (as determined by the participants' judgements) from the same dimensions in the unsuccessful organizations $(\mathrm{t}(62)=2.56, \mathrm{p}<.013$ for Human Relations dimension, $\mathrm{t}(62)=$ $1.86, \mathrm{p}<.057$ for Internal Process dimension, $\mathrm{t}(62)=1.79, \mathrm{p}<.068$ for Open system dimension, and $\mathrm{t}(62)=2.68$, $\mathrm{p}<.009$ ). The relationship between organizational culture and job satisfaction, where employees working in organizations with healthy organizational culture showed higher level of job satisfaction (e.g., Arnold \& Spell, 2006; Mansoor \& Tayib, 2010; McKinnon et al. 2003; Sabri et al. 2011), was used as another indication of the validity of the Egyptian version of the measure. Again, it was reasoned that if this version can distinguish between the organizational cultures in different levels of job satisfaction (high, medium, and low), that would be an indication of its validity. Again, data showed that this version of the measure was able to detect these differences. ANOVA analyses showed significant differences between the three levels of job satisfaction in the expected direction for the four dimensions of the measure $(\mathrm{F}(2,61)=6.13, \mathrm{p}<.004$ for Human Relations dimension, $\mathrm{F}(2,61)=2.86, \mathrm{p}<.057$ for Internal Process dimension, $\mathrm{F}(2,61)=5.34, \mathrm{p}<.007$ for Open system dimension, and $\mathrm{F}(2,61)=3.16, \mathrm{p}<.049$ for Rational Goal dimension).

\subsection{Procedure}

Data were collected in the summer of 2009. Participants were asked to fill the Organizational Climate Measure on a voluntary basis in their workplaces. Administration of the measure was either individually or in groups that ranged from 5 to 10 participants each. Before starting to administer the measure, a research assistant read the instructions and briefly explained the purpose of the study. Participants were assured that their personal data and responses would be kept confidential and used only for research purposes. Participants were told not to provide their names, workplace, their specific jobs, or any other information that can help in identifying their identity. Rather, they provided their demographic information (except for the names) in a sheet attached to their answered measure. On average, it took the participants 30 to 45 minutes to fill the inventory. After the participants finished filling the inventory, the research assistant briefed them more about the research and answered their questions for 5 minutes.

\section{Results}

Table 4 below shows basic data (means, standard deviations, minimum and maximum values, skewness and kurtosis values, and their standard errors) of the four dimensions of organizational culture and the scales constituting the Organizational Climate Measure $(\mathrm{n}=158)$. The results in the table indicate that the data follows the normal distribution curve as none of the skewness or kurtosis values reached or exceeded 2 of its SE.

Table 4. Means and standard deviations of major dimensions and scales in the organizational climate measure

\begin{tabular}{lllllllll}
\hline Dimensions \& Scales & $\mathbf{M}$ & SD & Min & Max & Skewness & SE & Kurtosis & SE \\
\hline Human Relations & $\mathbf{7 5 . 4 3}$ & $\mathbf{1 1 . 9 7}$ & $\mathbf{3 6 . 0 0}$ & $\mathbf{1 0 1 . 0 0}$ &.$- \mathbf{1 7 4}$ & $\mathbf{. 1 9 3}$ & $\mathbf{. 1 0 0}$ & $\mathbf{. 3 8 4}$ \\
autonomy & 11.11 & 2.45 & 6.00 & 16.00 & -.175 & .193 & .577 & .384 \\
Integration & 13.58 & 2.41 & 6.00 & 20.00 & -.355 & .193 & .500 & .384 \\
Involvement & 15.49 & 3.26 & 7.00 & 22.00 & -.210 & .193 & -.543 & .384 \\
support & 13.73 & 3.01 & 5.00 & 20.00 & -.277 & .193 & -.021 & .384 \\
Training & 10.54 & 2.53 & 4.00 & 16.00 & .286 & .193 & -.527 & .384 \\
Welfare & 10.98 & 2.64 & 4.00 & 16.00 & -.095 & .193 & -.608 & .384 \\
& & & & & & & & \\
Internal Process & $\mathbf{2 4 . 1 7}$ & $\mathbf{3 . 4 0}$ & $\mathbf{1 3 . 0 0}$ & $\mathbf{3 4 . 0 0}$ & $\mathbf{- . 1 0 8}$ & $\mathbf{. 1 9 3}$ & $\mathbf{. 3 4 8}$ & $\mathbf{. 3 8 4}$ \\
& & & & & & & & .384 \\
Formalization & 13.61 & 2.31 & 8.00 & 20.00 & .244 & .193 & -.109 & .384 \\
Tradition & 10.56 & 2.36 & 4.00 & 15.00 & -.361 & .193 & -.096 & .384 \\
& & & & & & & & \\
Open System & $\mathbf{4 3 . 4 9}$ & $\mathbf{8 . 1 1}$ & $\mathbf{1 6 . 0 0}$ & $\mathbf{6 2 . 0 0}$ & $\mathbf{. 0 6 9}$ & $\mathbf{. 1 9 3}$ & $\mathbf{. 0 2 3}$ & $\mathbf{. 3 8 4}$ \\
\hline
\end{tabular}




\begin{tabular}{lllllllll} 
Innovation & 16.07 & 3.43 & 6.00 & 23.00 & -.118 & .193 & -.360 & .384 \\
Outward Focus & 13.57 & 2.99 & 5.00 & 20.00 & .109 & .193 & -.241 & .384 \\
Reflexivity & 13.85 & 2.84 & 5.00 & 20.00 & -.124 & .193 & -.350 & .384 \\
Rational Goal & $\mathbf{7 5 . 4 5}$ & $\mathbf{1 0 . 8 1}$ & $\mathbf{3 5 . 0 0}$ & $\mathbf{1 0 1 . 0 0}$ & $\mathbf{- . 1 0 2}$ & $\mathbf{. 1 9 3}$ & $\mathbf{. 4 1 3}$ & $\mathbf{. 3 8 4}$ \\
& & & & & & & & \\
Clarity & 13.22 & 2.81 & 5.00 & 20.00 & -.080 & .193 & -.101 & .384 \\
Efficiency & 8.71 & 2.09 & 4.00 & 16.00 & .318 & .193 & .372 & .384 \\
Effort & 14.15 & 2.89 & 5.00 & 20.00 & .054 & .193 & -.125 & .384 \\
Feedback & 13.41 & 2.75 & 6.00 & 20.00 & .119 & .193 & -.345 & .384 \\
Pressure & 13.47 & 2.40 & 6.00 & 20.00 & .012 & .193 & .191 & .384 \\
Quality & 12.46 & 2.18 & 4.00 & 20.00 & -.198 & .193 & .131 & .384 \\
\hline
\end{tabular}

As for the main results, each of the four dimensions of organizational cultures and their component scales were compared across organizations with different types of ownership (private, public, and governmental), different sizes (large and small), and located in different regions in Egypt (Cairo, north Egypt, and South Egypt). Accordingly, a $3 \times 3 \times 2$ MANOVA of the data was conducted, where the four different dimensions of the Organizational Climate Measure and their subscales were the dependent variables, and the three types of ownership of large and small organizations in each of the three main regions in Egypt were the independent ones (see Table 5).

Table 5. Means of the scores on the four major dimensions constituting the organizational climate measure across the three independent variables (ownership, region, and size) and their interactions

\begin{tabular}{|c|c|c|c|c|c|c|c|c|c|c|}
\hline \multirow{2}{*}{$\begin{array}{l}\text { Main } \\
\text { Dimensions }\end{array}$} & \multirow{2}{*}{ 音 } & \multicolumn{3}{|c|}{ Large } & \multirow[t]{2}{*}{ Mean } & \multicolumn{3}{|c|}{ Small } & \multirow[t]{2}{*}{ Mean } & \multirow{2}{*}{$\begin{array}{c}\text { Grand } \\
\text { Mean }\end{array}$} \\
\hline & & North & Cairo & South & & North & Cairo & South & & \\
\hline HR & \multirow{4}{*}{ 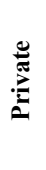 } & 84.00 & 75.30 & 67.00 & 75.43 & 84.73 & 79.10 & 75.00 & 79.61 & 77.52 \\
\hline IP & & 24.38 & 24.00 & 26.00 & 24.79 & 18.82 & 24.50 & 22.67 & 21.99 & 23.39 \\
\hline OS & & 48.88 & 47.60 & 42.00 & 46.16 & 49.18 & 46.95 & 42.33 & 46.15 & 46.16 \\
\hline RG & & 83.25 & 86.00 & 76.00 & 81.75 & 76.64 & 77.80 & 70.33 & 74.92 & 78.33 \\
\hline HR & \multirow{4}{*}{ 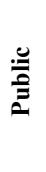 } & 86.00 & 77.20 & 78.33 & 80.51 & 85.00 & 70.00 & 77.67 & 77.56 & 79.04 \\
\hline IP & & 24.00 & 24.40 & 22.00 & 23.47 & 25.00 & 20.00 & 22.33 & 22.44 & 22.96 \\
\hline OS & & 45.00 & 40.20 & 41.33 & 42.18 & 45.50 & 43.00 & 40.33 & 42.94 & 42.56 \\
\hline RG & & 88.00 & 71.00 & 71.00 & 76.67 & 81.50 & 66.00 & 70.33 & 72.61 & 74.64 \\
\hline HR & \multirow{4}{*}{ 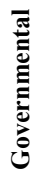 } & 72.57 & 74.63 & 69.68 & 72.29 & 69.13 & 76.20 & 71.22 & 72.18 & 72.24 \\
\hline IP & & 27.29 & 25.58 & 24.86 & 25.91 & 26.00 & 22.50 & 24.33 & 24.28 & 25.10 \\
\hline OS & & 38.86 & 42.90 & 38.77 & 40.18 & 39.00 & 44.50 & 41.11 & 41.54 & 40.86 \\
\hline RG & & 68.43 & 77.26 & 68.86 & 71.52 & 73.25 & 73.70 & 77.33 & 74.76 & 73.14 \\
\hline
\end{tabular}

HR $=$ Human Relations, $\mathrm{IP}=$ Internal Process, $\mathrm{OS}=$ Open System, $\mathrm{RG}=$ Rational Goal

In presenting the rest of the main results, each one of the four main dimensions will be presented separately, where data of the main dimension will be presented in regard to the three main independent variables (ownership, region, and size), followed by a description of each of these variables across the component scales comprising the main dimension. 


\subsection{Human Relations (Clan Culture)}

The results of the Human Relations dimension (see Table 6 below) indicate that there is a significant main effect of the ownership $(\mathrm{F}(2,143)=2.85, \mathrm{p}<.062)$, and Bonferroni post-hoc analysis showed that private organizations got significantly higher scores than governmental ones on this dimension (Mean Difference $=7.63, \mathrm{p}<.001$ ). On the other hand, there is no significant main effect of either the region or organization size. Also, none of the interactions is significant. However, organizations in North Egypt showed higher levels of Human Relations than their counterparts in the South (Mean Difference $=7.39, \mathrm{p}<.017$ ).

As for the detailed components of the Human Relations dimension as measured by its scales (autonomy, integration, involvement, support, training, and welfare), the main effect of ownership was significant in the case of autonomy $(\mathrm{F}(2,143)=3.61, \mathrm{P}<.030)$ and marginally significant in case of welfare $(\mathrm{F}(2,143)=2.69, \mathrm{p}$ $<$.072). Bonferroni Post hoc analyses of the autonomy scale showed that public organizations have more autonomy culture than governmental ones (Mean Difference $=1.93, \mathrm{p}<.010$ ), and private organizations provide more Welfare than governmental one (Mean Difference $=1.56, \mathrm{p}<.002$ ). Moreover, autonomy culture was affected by a significant interaction between Ownership and size $(\mathrm{F}(2,143)=3.09, \mathrm{p}<.049)$. Contrast analysis showed that while there is no significant difference between large and small organizations in case of public and governmental organizations, small, private organizations showed significantly more autonomy culture than large, private ones $(\mathrm{F}(1,139)=5.71, \mathrm{p}<.018)$. Again, the effect of ownership on autonomy culture was modified by the region effect as indicated by the marginally significant interaction between ownership and region $(\mathrm{F}(4,143)$ $=2.15, \mathrm{p}<.071)$. Contrast analysis showed that the difference between private and governmental organizations in autonomy culture was greater in North and South Egypt regions in comparison to Cairo, where this difference was limited and insignificant $(\mathrm{F}(1,135)=3.91, \mathrm{p}<.049)$. Although there was no significant main effect of ownership in any of the other Human Relations components, post hoc analyses showed that private organizations have more Involvement culture (Mean Difference $=1.52, \mathrm{p}<.022$ ), Support culture (Mean Difference $=1.67, \mathrm{p}$ $<.006$ ), and Training culture (Mean difference $=1.87, \mathrm{p}<.000$ ) than governmental ones. The effect of ownership on training culture was modified by the region variable as indicated by the significant interaction between these two variable $(\mathrm{F}(4,143)=2.80, \mathrm{p}<.029)$, and contrast analysis showed that training culture in private organizations in south Egypt was significantly lower than its counterparts in both Cairo and North Egypt, and this difference was insignificant for both public and governmental ownerships $(\mathrm{F}(1,135)=4.57, \mathrm{p}<.034)$. On the other hand, the main effect of region was significant in training $(F(2,143)=3.52, p<.033)$ and marginally significant for Integration $(F(2,143)=2.75, \mathrm{p}<.068)$. Post hoc analyses showed that South Egypt organizations have serious deficiency in training culture in comparison to organizations in both Cairo (Mean Difference $=1.85, \mathrm{p}<.000$ ) and North Egypt (Mean Difference $=2.02, \mathrm{P}<.001)$. Also, post hoc analyses of the Integration scale showed that organizations in Cairo have more integration than their counterparts in South Egypt (Mean Difference $=1.14, \mathrm{p}<.050$ ). Moreover, although there was no significant main effect of region in any of the other Human Relations components, post hoc analyses showed that Organizations in North Egypt have more autonomy culture than their counterparts in the Cairo (Mean Difference $=1.43, \mathrm{p}<.008$ ), and more Welfare culture than organizations in the South (Mean Difference $=1.45, \mathrm{p} .<.033$ ). Employees in the organizations in Cairo, on the other hand, have more Supervisory support than their counterpart in the South (Mean Difference $=$ $1.51, \mathrm{p}<.032$ ). Finally, there was no main effect of Size (large and small) in any of the components of the Human Relations dimension. A series of $\mathrm{T}$ tests showed no significant difference between large and small organizations on any of the six components of the human Relations dimension. 
Table 6. Mean of the scores on the human relations dimension and its components across the three independent variables (ownership, region, size) and their interactions

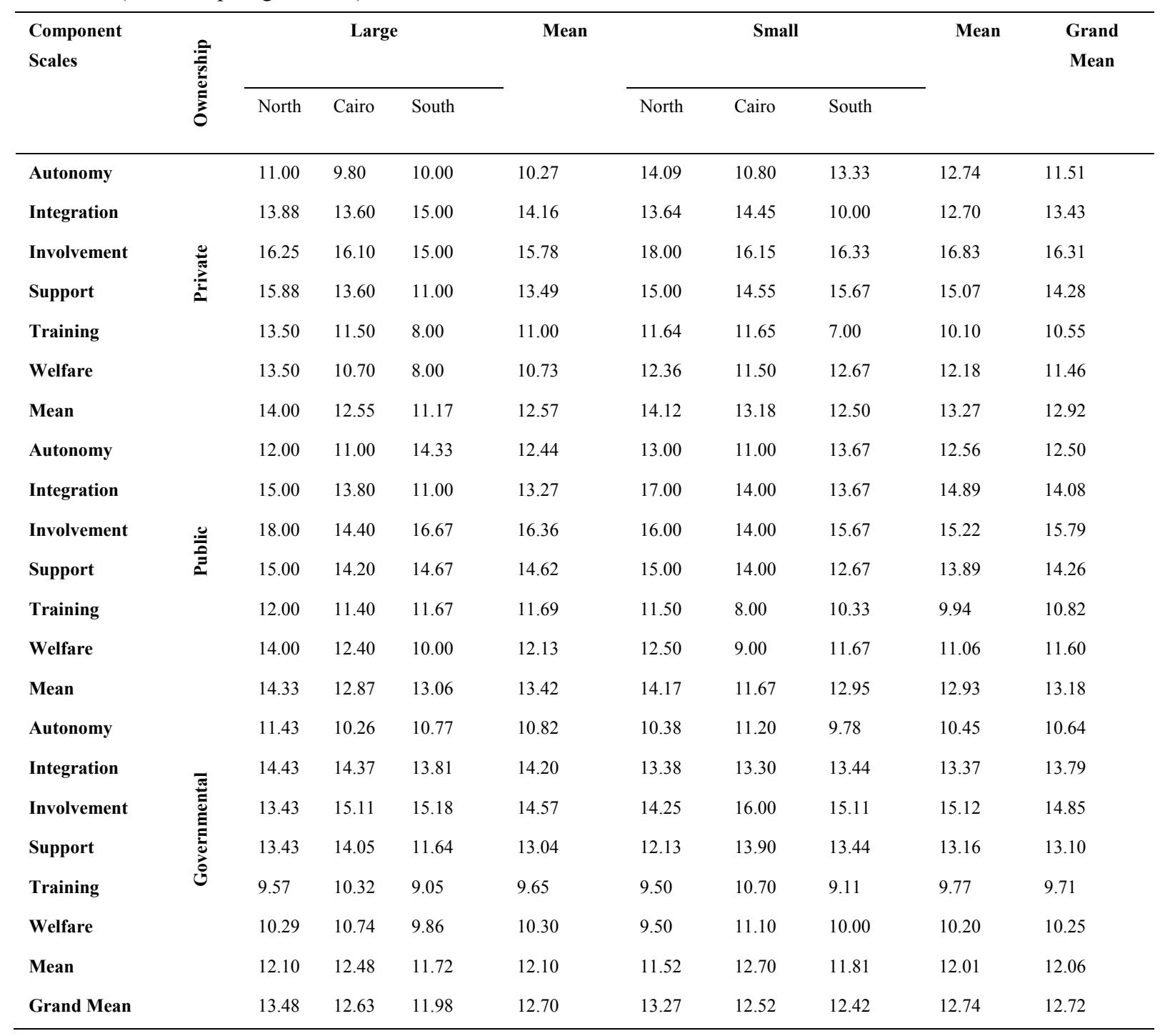

\subsection{Internal Process (Hierarchy Culture)}

Results of the Internal Process culture (see Table 7) show that there is a significant main effect of ownership ( $\mathrm{F}(2$, $143)=3.80, \mathrm{p}<.025)$, where governmental organizations have a significantly higher level of Internal Process culture than Private ones (Mean Difference $=1.88, \mathrm{p}<.003$ ). Also, there is significant main effect of the size $(\mathrm{F}(1,143)=4.91, \mathrm{p}<.029)$. A t test showed large organizations have significantly higher level of Internal Process culture than small ones $(\mathrm{t}(155)=.3 .22, \mathrm{p}<.002)$. Moreover, there is a significant interaction between ownership and region regarding Internal Process culture $(F(4,143)=4.07, p<.004)$. Contrast analysis showed that while organizations in Cairo and South Egypt have almost equal level of Internal Process culture regardless of ownership type, governmental organizations in North Egypt have significantly higher level of this culture than private and public organizations in this region $(\mathrm{F}(1,135)=14.56, \mathrm{p}<.000)$. There was no significant main effect of the region on this dimension.

As for the detailed components of Internal Process dimension as measured by its two scales of formalization and tradition, there was no significant main effect of ownership in either of them. However, formalization was affected by a significant interaction between ownership and region $(\mathrm{F}(4,143)=5.31, \mathrm{p}<.000)$. Contrast analysis showed that organizations in North Egypt have a much higher level of formalization culture in public and governmental organizations than their counterpart organizations in Cairo and South Egypt $(F(1,135)=15.21, p$ $<.000)$. As for the main effect of region it was significant in case of formalization $(F(2,143)=3.37, p<.037)$. And Bonferroni post hoc analysis showed that organizations in South Egypt have significantly higher level of 
formalization than organizations in North Egypt (Mean Difference $=1.26, \mathrm{p}<.051$ ). Also, there was a marginally significant effect of size in formalization $(F(1,143)=3.29, p<.067)$. T test showed that large organizations have more formalization culture than small ones $(\mathrm{t}(155)=2.09, \mathrm{p}<.038)$.

Table 7. Mean of the scores on the internal process dimension and its components across the three independent variables (ownership, region, size) and their interactions

\begin{tabular}{|c|c|c|c|c|c|c|c|c|c|c|}
\hline \multirow{2}{*}{$\begin{array}{l}\text { Component } \\
\text { Scales }\end{array}$} & \multirow{2}{*}{ 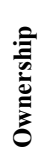 } & \multicolumn{3}{|c|}{ Large } & \multirow[t]{2}{*}{ Mean } & \multicolumn{3}{|c|}{ Small } & \multirow[t]{2}{*}{ Mean } & \multirow{2}{*}{$\begin{array}{l}\text { Grand } \\
\text { Mean }\end{array}$} \\
\hline & & North & Cairo & South & & North & Cairo & South & & \\
\hline Formalization & $\stackrel{\Xi}{\pi}$ & 15.13 & 14.90 & 13.00 & 14.34 & 10.64 & 14.35 & 12.00 & 12.33 & 13.34 \\
\hline Tradition & $\stackrel{i}{i=}$ & 9.25 & 9.10 & 13.00 & 10.45 & 8.18 & 10.15 & 10.67 & 9.67 & 10.06 \\
\hline Mean & & & & & 12.40 & & & & 11.00 & 11.70 \\
\hline Formalization & & 14.00 & 12.60 & 12.00 & 12.86 & 16.00 & 10.00 & 12.00 & 12.67 & 12.77 \\
\hline Tradition & $\frac{\varrho}{0}$ & 10.00 & 11.80 & 10.00 & 10.60 & 9.00 & 10.00 & 10.33 & 9.78 & 10.19 \\
\hline Mean & & & & & 11.73 & & & & 11.22 & 11.48 \\
\hline Formalization & 馬 & 15.57 & 14.05 & 13.46 & 14.36 & 14.88 & 12.60 & 13.56 & 13.68 & 14.02 \\
\hline Tradition & D̃ & 11.71 & 11.42 & 11.41 & 11.51 & 11.13 & 9.80 & 10.78 & 10.57 & 11.04 \\
\hline Mean & & 13.64 & 12.74 & 12.44 & 12.94 & 13.01 & 11.20 & 12.17 & 12.13 & 12.53 \\
\hline Grand Mean & & 12.61 & 12.31 & 12.15 & 12.36 & 11.64 & 11.15 & 11.56 & 11.45 & 11.90 \\
\hline
\end{tabular}

\subsection{Open System (Adhocracy Culture)}

Results of the Open System culture (see Table 8) showed a significant main effect of the ownership variable (F(2, $143)=3.67, \mathrm{p} .<.028)$. None of the other variables showed significant main effects or statistical interactions. Bonferroni post hoc analysis showed that private organizations have a significantly higher level of Open System culture than both public (Mean Difference $=5.81, \mathrm{p}<.036)$ and governmental (Mean Difference $=6.58, \mathrm{p}<.000)$ organizations. Also, post hoc analysis showed that organizations in south Egypt have significantly lower level of Open System cultures than their counterparts in both Cairo (Mean Difference $=4.98, \mathrm{p}<.005$ ) and North Egypt (Mean Difference $=4.72, \mathrm{p}<.026$ ).

As for the detailed components of Open System dimensions as measured by its three scales of innovation, outward focus, and reflexivity, there were significant main effects of ownership in innovation $(\mathrm{F}(2,143)=3.06$, $\mathrm{p}<.051)$ and outward focus $(\mathrm{F}(2,143)=4.87, \mathrm{p}<.009)$, but not in reflexivity. A series Post hoc Bonferroni analyses showed that private organizations have significantly more innovation cultures than both public (Mean Difference $=2.36, \mathrm{p}<.041$ ) and governmental (Mean Difference $=2.57, \mathrm{p}<.000$ ) organizations. Similarly, post hoc analyses showed that private organizations have significantly more outward focus cultures than both public (Mean Difference $=1.83, \mathrm{p} .<.085)$ and governmental (Mean Difference $=2.45, \mathrm{p} .<.000)$ organizations. As for the reflexivity culture, post hoc analysis showed that it was significantly more dominant in private than governmental organizations (Mean Difference $=1.55, \mathrm{p}<.006$ ). On the other hand, there was no significant main effect of region in any of the three components of Open System culture. However, there was a significant statistical interaction between region and ownership in innovation $(F(4,143)=2.58, p<.040)$, and contrast analysis showed that the difference between private and governmental organizations in North Egypt was significantly higher than the counterpart differences in Cairo and South Egypt organizations $(F(1,135)=9.35, p$ $<.003$ ). A series of Bonferroni post hoc analyses showed that Organizations in South Egypt had significantly lower levels of innovation cultures than their counterparts in both Cairo (Mean Difference $=1.96, p<.029$ ) and north Egypt (Mean Difference $=2.24, \mathrm{p}<.008$ ). Similarly, organizations in South Egypt were shown to be less than their counterparts in Cairo in terms of outward focus (Mean Difference $=1.81, \mathrm{p}<.005$ ) and reflexivity 
(Mean Difference $=1.48, \mathrm{p}<.023$ ). Regarding the size variable, there was no main effect of it in any of the Open System scales. However, smaller organizations showed significantly higher level of innovation than large ones $(\mathrm{t}(155)=2.08, \mathrm{p}<.039)$.

Table 8. Mean of the scores on the open systems dimension and its components across the three independent variables (ownership, region, size) and their interactions

\begin{tabular}{|c|c|c|c|c|c|c|c|c|c|c|}
\hline \multirow{2}{*}{$\begin{array}{l}\text { Component } \\
\text { Scales }\end{array}$} & \multirow{2}{*}{ 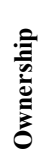 } & \multicolumn{3}{|c|}{ Large } & \multirow[t]{2}{*}{ Mean } & \multicolumn{3}{|c|}{ Small } & \multirow[t]{2}{*}{ Mean } & \multirow{2}{*}{$\begin{array}{l}\text { Grand } \\
\text { Mean }\end{array}$} \\
\hline & & North & Cairo & South & & North & Cairo & South & & \\
\hline Innovation & & 18.50 & 16.90 & 16.00 & 17.13 & 19.46 & 17.25 & 14.00 & 16.90 & 17.02 \\
\hline Outward Focus & 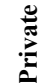 & 15.75 & 14.80 & 13.00 & 14.52 & 15.00 & 15.20 & 14.67 & 14.96 & 14.74 \\
\hline Reflexivity & & 14.63 & 15.90 & 13.00 & 14.51 & 14.73 & 14.50 & 13.67 & 14.30 & 14.41 \\
\hline Mean & & 16.29 & 15.86 & 14.00 & 15.38 & 16.40 & 15.65 & 14.11 & $15 / 39$ & 15.39 \\
\hline Formalization & & 17.00 & 13.80 & 15.67 & 15.49 & 17.50 & 15.00 & 15.33 & 15.94 & 15.72 \\
\hline Outward Focus & $\frac{.0}{0}$ & 13.00 & 14.00 & 13.33 & 13.44 & 13.50 & 13.00 & 12.00 & 12.83 & 13.14 \\
\hline Reflexivity & & 15.00 & 12.40 & 12.33 & 13.24 & 14.50 & 15.00 & 13.00 & 14.17 & 13.71 \\
\hline Mean & & 15.00 & 13.40 & 13.78 & 14.06 & 15.17 & 14.33 & 13.44 & 14.31 & 14.19 \\
\hline Innovation & & 13.86 & 15.63 & 14.36 & 14.62 & 14.38 & 16.90 & 15.00 & 15.43 & 15.03 \\
\hline Outward Focus & 氖 & 11.71 & 13.47 & 12.18 & 12.45 & 11.88 & 13.70 & 12.22 & 12.60 & 12.53 \\
\hline Reflexivity & ¿ & 13.29 & 13.79 & 12.23 & 13.10 & 12.75 & 13.90 & 13.89 & 13.51 & 13.31 \\
\hline Mean & & 12.95 & 14.43 & 12.92 & 13.39 & 13.00 & 14.83 & 13.70 & 13.85 & 13.62 \\
\hline Grand Mean & & 14.75 & 14.52 & 13.57 & 14.28 & 14.86 & 14.94 & 13.75 & 14.52 & 14.40 \\
\hline
\end{tabular}

\subsection{Rational Goal (Market Culture)}

The results of the Rational Goal Culture (Table 9) indicate that there was no main effect of any of the three studied variables (welfare, region, and size) or any interaction among them. However, post hoc analyses showed that private organizations have more rational goal cultures than governmental ones (Mean Difference $=6.39, \mathrm{p}$ $<.003$ ), and organizations in Cairo have more rational goal cultures than their counterparts in South Egypt (Mean Difference $=6.30, \mathrm{p}<.009$ ).

As for the detailed components of Rational Goal dimension as measured by its six scales (clarity of goals, efficiency, effort, performance feedback, pressure to produce, and quality), there were significant main effects of ownership in clarity of goals $(\mathrm{F}(2,143)=3.21, \mathrm{p}<.044)$, efficiency $(\mathrm{F}(2,143)=8.23, \mathrm{p}<.000)$, and pressure to produce $(\mathrm{F}(2,143)=3.11, \mathrm{p}<.048)$. A series of Bonferroni post hoc analyses showed that private organizations were higher than their governmental counterparts in terms of clarity of goals (Mean Difference $=1.96, p<.000$ ), efficiency (Mean Difference $=1.36, \mathrm{p}<.057$ ), pressure to produce $($ Mean Difference $=1.45, \mathrm{p}<.001$ ), and quality (Mean Difference $=.851, \mathrm{p}<.066$ ). Also, data showed that ownership interacted significantly with size in efficiency $(\mathrm{F}(2,143)=3.85, \mathrm{p}<.024)$, performance feedback $(\mathrm{F}(2,143)=4.65, \mathrm{p}<.011)$, and pressure to produce cultures $(\mathrm{F}(2,143)=3.58, \mathrm{p}<.031)$. A series of contrast analyses showed that large organizations scored higher than small ones in private sector, and this difference was significantly higher than the counterpart differences in public and governmental organizations. And this was the case for efficiency culture $(\mathrm{F}(1,139)=$ $6.54, \mathrm{p}<.012)$, performance feedback culture $(\mathrm{F}(1,139)=4.89, \mathrm{p}<.029)$, and pressure to produce culture $(\mathrm{F}(1$, $139)=10.17, \mathrm{p}<.002)$. Also, ownership interacted with region in both effort $(\mathrm{F}(4,143)=3.61, \mathrm{p}<.008)$ and quality cultures $(\mathrm{F}(4,143)=2.46, \mathrm{p}<.049)$. Contrast analyses showed that for both cultures of effort and quality, the private organizations in Cairo and North Egypt scored higher than public and governmental organizations. However, the picture was different in North Egypt, where public organizations scored higher than private and governmental ones in both effort $(\mathrm{F}(1,135)=9.94, \mathrm{p}<.002)$ and quality $((\mathrm{F}(1,135)=3.75, \mathrm{p}<.055)$ scales. On 
the other hand, data showed main effects of region in both effort $(F(2,143)=2.99, \mathrm{p}<.054)$ and quality $(\mathrm{F}(2$, $143)=7.71, p<.001)$. A series of Bonferroni post hoc analyses showed that organizations in Cairo were statistically higher than their counterparts in South Egypt in terms of clarity of goals (Mean Difference $=1.24, \mathrm{p}$ $<.064$ ), pressure to produce (Mean Difference $=1.39, \mathrm{p}<.005$ ), and quality (Mean Difference $=1.56, \mathrm{p}<.001$ ) components. Also, Organizations in North Egypt were significantly higher than their counterparts in South Egypt in terms of pressure to produce (Mean Difference $=1.20, \mathrm{p}<.046$ ), and quality (Mean Difference $=1.50, \mathrm{p}$ $<.005)$. A significant interaction between region and size affected quality culture $((\mathrm{F}(2,143)=3.68, \mathrm{p}<.028)$, and contrast analysis showed that quality culture in large organizations was higher than small one in both Cairo and North Egypt though small organizations in South Egypt scored higher than large ones in this culture ((F $(1$, $148)=5.13, \mathrm{p}<.025)$. On the other hand, there was a main effect of size in efficiency $(F(1,143)=4.07, p$ $<.046)$, and large organizations have statistically higher level of efficiency than small ones $(t(155)=2.144, p$ $<.034)$.

Table 9. Mean of the scores on the rational goal dimension and its components across the three independent variables (ownership, region, size) and their interactions

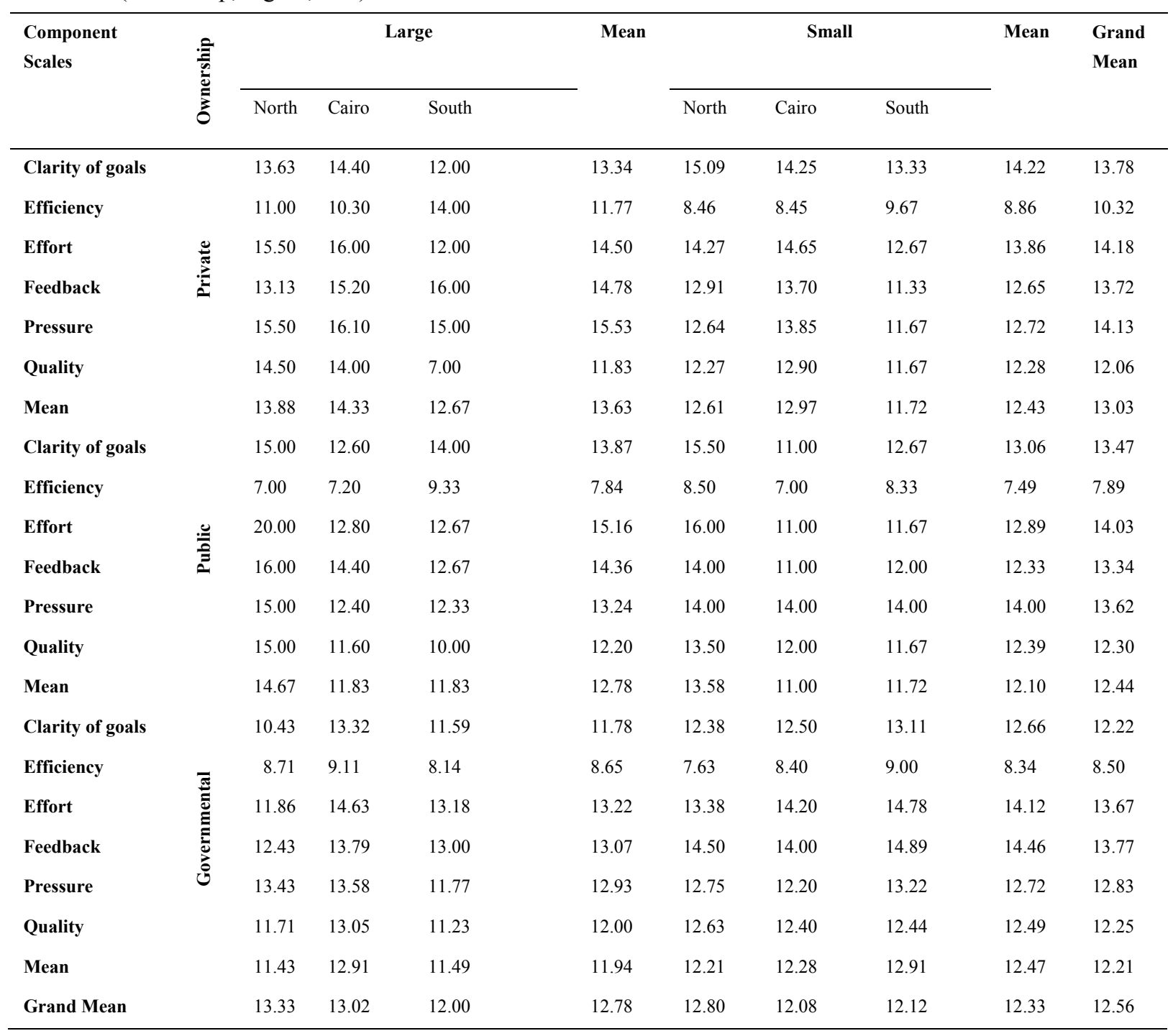

\section{Discussion}

Unlike most other studies, which tried to study the effect of organizational culture on different aspects of performance and work environment, the current study is an attempt to study the effect of three main variables on organizational culture in Egyptian workplaces. These variables are ownership type (private, public, and governmental), region (Cairo, North Egypt, and South Egypt), and Size (large and small organizations). The 
conceptualization of organizational culture, as studied in current study, is based on the Competing Values Framework developed by Cameron and Quinn (2006). According to this theory, organizational culture is not a homogenous phenomenon. Rather, it is a multidimensional one that consists of four major dimensions or quadrants: Clan (Human Relations), Hierarchy (Internal Process), Open System (Adhocracy), and Rational Goal (Market). Each of these dimensions represents a different aspect of culture. The instrument used in the study, Organizational Climate Measure, was based on this theory and went further to specify main components that comprise each dimension.

In the current section, the main effects of the three mentioned-above variables (ownership, region, and size) on the organizational culture and their interactions will be discussed in relation to relevant literature and Egyptian cultural, socio-political context.

As for the ownership variable, the results indicate that the most noticeable difference was probably between private and governmental organizations. Private organizations were shown to be perceived by their employees as higher than governmental counterparts in Human Relations culture (involvement, supervisory support, welfare, and training), Open System culture (innovation, outward focus, and reflexivity), and Rational Goal culture (clarity of goals, efficiency, pressure to produce, and quality). On the other hand, governmental organizations were higher than private ones in Internal Process culture (formalization and tradition). Moreover, public organizations didn't differ significantly from either private or governmental ones in the Human Relations, Internal process, or Rational Goal dimensions of organizational culture, except that employees in these public organizations showed higher level of autonomy than their counterparts in governmental ones. However, public organizations were shown to have lower level of Open System culture (innovation, outward focus, and reflexivity) than private organizations.

These results in general are consistent with the reasoning that governmental organizations lack profit motive, incentives, and personal responsibility, which affect their performance. The long history of the governmental and public sector dominance in Egypt (Since mid-1950s until mid-1990s), that was accompanied by mismanagement and corruption, created what might be known as the "no-owner company" culture (Vo \& Nguyen, 2011). Accordingly, lack of resources and motivation to improve might account for the findings of having less Human Relations and Open System cultures in governmental organizations as limited resources would negatively affect employee welfare or training. Also, employee creativity, autonomy, or involvement can be hardly encouraged in such a context. Moreover, the state support of the private organizations encouraged them to develop a more competitive, market-oriented culture. The results of the current study, in this regard, are consistent with findings from other countries with similar economic structures and transformations (Cunha, 2000; Daniel, Stephanie, \& Paulo, 2004; Ferrreira et al. 2004; Forster \& Mouly, 2006; Tsamenyi, Onumah, \& Tetteh-Kumah, 2010, Vo \& Nguyen, 2011). In general, these results found that private organizations were more oriented toward people training and welfare, on one hand, and toward market and competition, on the other hand. The dominance of the formalization component in the governmental organizations is consistent with Shehata' (2005) findings about the dominance of authoritarian, rigid, and hierarchically-based system of authority in state owned major organizations in Egypt.

However, it should be emphasized that the failure of governmental organizations to develop healthy cultures that support Human relations, Open System, and Rational Goals might reflect corruption and lack of transparency in these organizations, rather than a structural defect in their systems. As Owusu (2005) notices, the assumptions that all state-owned organizations are inefficient is questionable, and some of governmental organizations in Third World countries are run efficiently because of their importance for the survival of the regimes in these countries. More will be said about this point on discussing the interactions among the independent variables in the current study.

As for the region dimension, the most salient result was that organizations in South Egypt were shown to have significantly lower level of Human Relations, Open System, and Rational Goal culture than their counterparts in Cairo and North Egypt. Specifically, South Egypt organizations were lower than their counterparts in Cairo in terms of integration and supervisory support in the Human Relations dimension, reflexivity and outward focus in the Open System dimension, and clarity of goals, pressure to produce, and quality in Rational Goal dimension. Again, Southern Egypt organizations were lower than their Northern Egypt counterparts in terms of welfare in the Human Relations dimension, and pressure to produce and quality in the Rational Goal dimension. Moreover, South Egypt organizations showed lower level of integration and innovation than their counterparts in both Cairo and North Egypt. On the other hand, South Egypt organizations showed a higher level of Internal Process culture (formalization) than their counterparts in North Egypt but not in Cairo. Finally, employees in North Egypt organizations seemed to have more autonomy than their counterparts in Cairo. 
The results are consistent with the fact the South Egypt is the least developed region in the whole country, in terms of education, services, and infrastructure. Though the recent development plans in this region, Egyptian governments traditionally have a long history of neglecting South Egypt. This resulted in less developed organizations, less number of large ones, and less private investment in this region. This lack of resources and services was reflected in traditional workplaces that care mainly about formality of work and are run in traditional way. Also, this lack of resources can explain the decrease of Human Relations cultural aspects, and the decline of market-oriented performance in different organizations in this region. Moreover, South Egypt is known to be more conservative region than both Cairo and North Egypt. Again, this can explain the dominance of the tradition component of the Internal Process culture, and the lack of innovation and outward focus components of the Open System culture in the organizations in this region. On the other hand, the results are consistent with a broad literature that emphasizes the importance of the regional/national culture on organizational culture. In the early days of studying organizational culture, Hofstede and his colleagues (Hofstede, 1980; 1991; Hofstede, Hofstede, \& Minkov, 2010) studied cultural differences among 116.000 of IBM employees from 72 countries and 20 languages. Hofstede and his colleagues defines six dimensions, along which different cultures can be differently located (power distance, uncertainty avoidance, individualism vs. collectivism, masculinity vs. femininity, long term orientation, and indulgence vs. restraint). Hofstede's results indicated the multinational companies need to take local and national culture into consideration while they are building their organizational culture. More recently, House and his colleagues (House, Hanges, Javidan, Dorman, \& Gupta, 2004) initiated the GLOBE study of leadership, national culture, and organizational culture in 62 countries. They identified nine cultural dimensions to be considered in evaluating and studying national or organizational cultures (performance orientation, uncertainty avoidance, humane orientation, institutional collectivism, in-group collectivism, assertiveness, gender egalitarian, future orientation, and power distance). Throughout this approach, the implicit assumption is that organizational values and culture should be consistent with the values and culture of the region in which it is nested and must get a minimum level of approval from society in order to function effectively (Sagiv \& Schwartz, 2007). Moreover, the effect of national or regional culture can be indirect through the values and norms a culture would cultivate in its members. Although organizations build their own cultures and are involved in a long socialization process to their employees, they should work hard to reduce discrepancies and contradictions between employees' values and organizational values, and those who are successful in building such compatible culture are having less job turnover and more loyal employees (Edington \& Bruce, 2006; Wang, 2001).

As for the size variable, the results indicated that large organizations had higher levels of Internal Process (formalization) and Rational Goal (efficiency) cultures than small organizations. On the other hand, small organizations showed higher level of innovation than large ones. This result is consistent with the fact that majority of small organizations are in South Egypt and rural areas of North Egypt. And relationships in these areas are based on face to face communication and kinship relations (Bonner, 1998), which gives more space to individualized timeframes, flexible rules, and more involvement in decision making. Accordingly, such culture in small organizations allows experimentation and encourages innovation. It also allows more personal relations between managers and employees, which result in much less formal relationship than in large organizations. However, small organizations in Egypt are usually based on limited resources in terms of capital and facilities, and give less salary and opportunities for training than their large counterparts. Accordingly, it comes as no surprise that large organizations were perceived to be more efficient. On the other hand, the results of the current study, in regard to organization size, reflect an old finding in the literature that changes in the size of an organization result in changes in its structure, dynamics, leadership style, and its efficiency, although it is difficult to determine an optimal size for an organization. According to Alvesson (2002), as the organizational size exceeds 300 employees, it shows deterioration in work quality and more bureaucracy. In general, small organizations were found to have more positive organizational culture, more consultative management, and their employees had higher morale (Connell, 2001). Also, small organizations were found to be more flexible, with less bureaucracy and less rigidity in decision making (Carlsson, 1999; Kuratko, Goodale, \& Hornsby, 2001; Gray, Densten, \& Sarros, 2003). However, as small organizations usually have limited human and financial resources and lack wide professional expertise, they tend to be less able to invest in training and development, respond to challenges, or absorb market fluctuations than their large counterparts (McAdam, 2000; Thong \& Yap, 1995). This pattern of results, where small organizations are perceived as more innovative but less efficient and productive than large ones, is consistent with the pattern of results in the current study.

Although studying the main effects of the independent variables in the current study has probably revealed an interesting pattern of results, studying the effect of their interaction on some of the organizational culture components should reveal a more rich and dynamic pattern. For example, the amount of individual responsibility 
and margin of flexibility employees have in performing their work and in decision making (the autonomy component) were subject to two significant interactions between ownership and region, on one hand, and between ownership and size on the other hand. The first interaction (between ownership and region) showed that there was no difference between different types of ownership in autonomy given to employees in organizations in Cairo, while organizations in South Egypt and North Egypt were perceived to allow their employees more autonomy in public organizations followed by private and governmental ones. On the other hand, the second interaction between ownership and size showed that there was no difference between small and large governmental organizations in terms of the autonomy allowed for their employees, while small public and private organizations allowed their employees more autonomy than large ones. Taken together, these results indicate that organizations in Cairo allow their employees the lowest level of autonomy, which is consistent with central nature of the capital, where most organizations have their own headquarters. Another aspect of this result is that public organizations outside Cairo allow their employees more autonomy than both governmental and private organizations. Moreover, private organizations in Cairo tend to allow less autonomy to their employees than public ones. This result again indicates that Egyptian private organizations in general allow less autonomy to their employees than what is common in the literature. This result can be attributed to the fact that many Egyptian private organizations, especially outside Cairo, are small family businesses controlled by hierarchical family structure in conservative communities.

Another interesting aspect is the effect of the significant interaction between ownership and region on training. It was found that private organizations are perceived to allow better training and development for their employees than both governmental and public ones only in Cairo and North Egypt, while private organizations in South Egypt were found to be way behind public and governmental organizations in this regard.

The interaction of the ownership and region effects on formalization adds more details to the above mentioned picture. That is, formalization was found to be higher in governmental and public organizations than in private ones in both North Egypt and South Egypt. Private organizations in Cairo, however, were perceived to have more formalization than their public and governmental counterparts. This, again, is consistent with the fact that organizations in the capital, especially large ones, are run based on hierarchical, rigid management and decision making. This central aspect of the organizations in Cairo might be responsible for the very similar level of innovation in private and governmental organizations in Cairo, while governmental organizations were perceived as less innovative than their private and public counterparts in both South Egypt and North Egypt regions. The central role of the organizations in Cairo and the relative weakness of private organizations outside Cairo (especially in the South) can be seen through the interactions between the effects of ownership and region on the perceived quality of the work and the effort required for performing it. The general trend in these two interactions is that governmental organizations are generally perceived to be lower than public and private ones in work quality and effort but governmental organizations in South Egypt were found to have higher level of quality and effort than their public and private counterparts. Also, these organizational culture components (quality and effort) were perceived to be almost equally high in private and governmental organizations in Cairo. On the other hand, private organizations in North Egypt were perceived to be higher in both quality and effort components than their public and governmental counterparts. These results indicate that private organizations in the South are less advanced than their counterparts in Cairo and North Egypt, and that governmental organizations in Cairo are more advanced than their counterparts in South and North Egypt regions. The interaction between the effects of region and size on quality supports these results. This interaction showed that while larger organizations are perceived to have higher level of quality than small ones in Cairo and North Egypt, small organizations in the South were perceived to have higher level of quality than larger ones.

Taken together these interaction results add more realistic, complicated details to the patterns of results derived from the main effect results. Going beyond the general finding of the superiority of private, North, and large organizations over governmental, South, and small organizations, respectively, three general conclusions need to be highlighted taking into consideration the interaction between these variable. The first conclusion is that although private organizations in general perceived to be high in Human Relations, Open System, and Rational Goal dimensions, they are less competent outside Cairo (especially in South Egypt) as they are perceived to provide their employees less level of autonomy and training than their counterparts in Cairo and North Egypt. This can be attributed to the lower level of infrastructure, financial restraints private organizations might have, and the dominance of agricultural economy in South Egypt. The second conclusion is that although governmental organizations are perceived to be less than their private counterparts in many aspects of organizational culture, these organizations in Cairo were found to have stronger organizational culture than their counterparts in South and North Egypt regions. This can be attributed to the central role of Cairo the major 
cosmopolitan city in Egypt with more than 16 Million persons living in it and, like most capitals in the Third World countries, have the headquarters of most official and governmental organizations. Third conclusion is that public organizations especially in Cairo and North Egypt can be perceived to outperform the private ones. This might be due to the fact that public organizations, which are owned by the state, don't have the financial restraints the private organizations in these regions might have, and have more flexible management than governmental ones.

Thus, this study emphasized the importance of studying the organizational culture of different organizations as a dependent variable that is affected by the economic and social context in which these organizations work, and three factors were considered in this study (ownership, regional culture, and size). It is argued here that this approach helps researchers, mangers, and decision makers to better understand the intricacies of the functionality of these organizations and the effect of the interaction of these factors on the organizational culture and performance in these organizations. The current study, accordingly, is an addition to a trend of research in the organizational culture that supports an alignment between national/regional culture and organizational culture, and help to avoid wide generalizations that don't take the wide social and cultural contexts into account when considering economic development. Further studies in this direction are still needed to consider these aspects of organizational culture in specific fields or vocations, among different levels of employees (managers, staff, or workers), and in different stages of organization development.

\section{Acknowledgments}

The author is grateful for Charles Clifton at the University of Massachusetts Amherst for valuable suggestions and comments on an earlier draft, and for two anonymous reviewers of IJPS for help and comments. He is also thankful for Abdelmawgood Farahat for being very helpful in collecting the data.

\section{References}

Arnold, T., \& Spell, S. (2006). The relationship between justice and benefits satisfaction. Journal of Business and sychology, 20, 599-620. http://dx.doi.org/10.1007/s10869-005-9006-1

Alvesson, M. (2002). Understanding organizational culture. London: Sage Publications.

Bagraim, J. (2001). Organizational psychology and workplace control: The instrumentality of corporate culture. South African Journal of Psychology, 31, 43-49. http://dx.doi.org/10.1177/008124630103100306

Baker, K. (2002). Organizational Culture. Retrieved from http://www.au.af.mil/au/awc/augate/doe/benchmark/11-Organizational Culture. PDF [accessed on 9/15/2009].

Bonner, K. (1998). Reflexivity, sociology and the rural-urban distinction in Marx, Tonnies and Weber. The Canadian Review of Sociology and Anthropology, 35, 165-189. http://dx.doi.org/10.1111/j.1755-618X.1998.tb00227.x

Bulach, C., Lunenburg, F., \& Potter, L. (2012). Creating a culture for high-performing schools: A comprehensive approach to school reform (2nd ed.). Lanham, MD: Rowman \& Littlefield.

Cameron, K., \& Quinn, R. (2006). Diagnosing and changing organizational culture: Based on the competing values framework. San Francisco, CA: Jossey-Bass.

Carlsson, B. (1999). Small business entrepreneurship and industrial dynamics. In Z. L. Acs (Ed.), Are small firms important? Their role and impact (pp. 99-110). Boston, MA: Kluwer Academic Publishers. http://dx.doi.org/10.1007/978-1-4615-5173-7_6

Chang, S., \& Lee, M. (2007). A study on the relationship among leadership, organizational culture, the operation of learning organization and employees' job satisfaction. Learning Organization, 14, 155-185. http://dx.doi.org/10.1108/09696470710727014

Clampitt, P. G. (2001). Communicating for managerial effectiveness (2nd ed.). Thousand Oaks: Sage.

Connell, J. (2001). Influence of firm size on organizational culture and employee morale. Journal of Management Research, 1, 220-232.

Cunha, R. (2000). The impact of privatization in Portugal. In R. J. Burke, \& C. L. Cooper (Eds.), The organization in crisis, downsizing, restructuring and Privatization. Brazil Blackwell: Oxford University Press. 
Daniel, R., Stephanie, H., \& Paulo, G. (2004). Corporate culture and organizational effectiveness: Is Asia different from the rest of the World? Organizational Dynamics, 33, 98-109. http://dx.doi.org/10.1016/j.orgdyn.2003.11.008

Denison, D., Hooijberg, R., \& Quinn, R. (1995). Paradox and performance: Toward a theory of behavioral complexity in managerial leadership. Organizational Science, 6, 524-540. http://dx.doi.org/10.1287/orsc.6.5.524

Edgington, R., \& Bruce, G. (2006). Organizational culture: Preferences and realities. GMAC Research Reports. RR-06-11.

Ferreira, M., Assmar, E., Estol, K., Chagas, M., \& Cisne, M. (2004). Organizational culture in Brazilian public and private companies. In B. N. Setiadi, A. Supratiknya, W. J. Lonner, \& Y. H. Poortinga (Eds.), Ongoing Themes in Psychology and Culture: Selected Papers from the Sixteenth International Congress of the International Association for Cross-Cultural Psychology (online Edition). Melbourne, FL: International Association for Cross Cultural Psychology. Retrieved from http://www.iaccp.org

Forster, T., \& Mouly, V. (2006). Privatization in a developing country: Insights from the Gambia. Journal of Organizational Change, 19, 250-265. http://dx.doi.org/10.1108/09534810610648942

Fukuyama, F. (1992). The End of History and the Last Man. Free Press.

Gray, J., Densten, I., \& Sarros, J. (2003). Size matters: Organizational culture in small, medium, and large Australian organizations. Working Paper Series: Working paper 24/03. Monash University: Department of Management.

Hodgkinson, G. (2003). The interface of cognitive and industrial, work and organizational psychology. Journal of Occupational and Organizational Psychology, 76, 1-25. http://dx.doi.org/10.1348/096317903321208862

Hofstede, G. (1980). Culture's consequences, international differences in work-related values. Beverly Hills: Sage.

Hofstede, G. (1991). Cultures and organizations: Software of the mind. London: McGraw-Hill.

Hofstede, G., Hofstede, G., \& Minkov, M. (2010). Cultures and organizations: Software of the mind Intercultural cooperation and its importance for survival (3rd ed.). New York: McGraw-Hill.

House, R., Hanges, P., Javidan, M., Dorman, P., \& Gupta, V. (2004). Culture, leadership, and organizations: The GLOBE study of 62 societies. Thousand Oaks: Sage Publications.

Islam, T., Khan, S., Aamir, M., \& Ahmad, U. (2012). Turnover intentions: The influence of organizational learning culture and multi foci citizenship behaviors. Middle-East Journal of Scientific Research, 12, 650-661.

Kitts, J., \& Trowbridge, P. (2007). Shape up or ship out: Social networks, turnover, and organizational culture. Computational and Mathematical Organization Theory, 13, 333-353. http://dx.doi.org/10.1007/s10588-007-9015-x

Kotter, J. (2012). Corporate culture and performance. New York, NY: Free Press.

Kuratko, D., Goodale, J., \& Hornsby, J. (2001). Quality practices for a competitive advantage in small firms. Journal of Small Business Management, 39, 293-312. http://dx.doi.org/10.1111/0447-2778.00027

Lunenburg, F. (2011). Organizational culture-performance relationships: Views of excellence and theory Z. National Forum of Educational Administration and Supervision Journal, 29, 1-10.

Mansoor, M., \& Tayib, M. (2010). An empirical examination of organizational culture, job stress, job satisfaction within the indirect tax administration in Malaysia. International Journal of Business and Social Sciences, 1, 81-95.

McAdam, R. (2000). The implementation of reengineering in SMEs: A grounded study. International Small business Journal, 18, 29-45. http://dx.doi.org/10.1177/0266242600184002

McKinnon, L., Harrison, L., Chow, W., \& Wu, A. (2003). Organizational culture: Association with commitment, job satisfaction, propensity to remain and information sharing in Taiwan.International Journal of Business Study, 11, 25-44.

Nelson, R. (2011). Adversity, organizational culture and executive turnover in a Brazilian manufacturer. Organizational Studies, 32, 407-425. http://dx.doi.org/10.1177/0170840610397479 
Ogbonna, E., \& Harris, L. (2000). Leadership style, organizational culture and performance: Empirical evidence from UK companies. International Journal of Human Resource Management, 11, 766-788. http://dx.doi.org/10.1080/09585190050075114

Ottaway, M., \& Hamzawy, A. (2011). Protest movements and political change in the Arab World. Policy Outlook: Carnegie endowment for international peace.

Ouchi, W. (1981). Theory Z: How American business can meet the Japanese challenge? Reading, MA: Addison-Wesley. http://dx.doi.org/10.1016/0007-6813(81)90031-8

Owusu, F. (2005). Organizational culture, performance and public sector reforms in Africa: The Ghanaian case. Paper presented in the International Conference on Shared Growth in Africa. Accra, Ghana (July, 21-22).

Pascale, R., \& Athos, A. (1982). The art of Japanese management: Applications for American Executives. New York, NY: Simon \& Schuster.

Patterson, M., Warr, P., \& West, M. (2004). Organizational climate and company performance: The role of employee affect and employee level. Journal of Occupational and Organizational Psychology, 77, 193-216. http://dx.doi.org/10.1348/096317904774202144

Patterson, M., West, M., Shackleton, V., Dawson, J., Lawthom, R., Maitlis, S., Robinson, D., \& Wallace, A. (2005). Validating the organizational climate measure: Links to managerial practices, productivity and innovation. Journal of Organizational Behavior, 26, 379-408. http://dx.doi.org/10.1002/job.312

Peter, T., \& Waterman, R. (2006). In search of excellence: Lessons from America's best run companies. New York, NY: Collins Business Essentials.

Pettigrew, A. (1979). On studying organizational culture. Administrative Science Quarterly, 24, 570-581. http://dx.doi.org/10.2307/2392363

Pettigrew, A., Woodman, R., \& Cameron, K. (2001). Studying Organizational Change and Development: Challenges for Future Research. The Academy of Management Journal, 44, 697-713. http://dx.doi.org/10.2307/3069411

Sabri, P., Ilyas, M., \& Amjad, Z. (2011). Organizational culture and its impact on the job satisfaction of the University teachers of Lahore. International Journal of Business and Social Science, 2, 121-128.

Sagiv, L., \& Schwartz, S. (2007). Cultural values in organizations: Insights for Europe. European Journal of International Management, 1, 176-190. http://dx.doi.org/10.1504/EJIM.2007.014692

Schein, E. (1992). Organizational Culture and Leadership (2nd ed.). San Francisco, CA: Jossey-Bass.

Schneider, B. (1987). The people make the place. Personnel Psychology, 40, 437-453. http://dx.doi.org/10.1111/j.1744-6570.1987.tb00609.x

Shehata. S. (2003). In the Basha's house: The organizational culture of Egyptian public-sector enterprise. International Journal of the Middle East Studies, 35, 103-132. http://dx.doi.org/10.1017/S0020743803000059

Solidarity Center. (2010). Justice for all: The struggle for worker rights in Egypt. Washington, DC: Solidarity Center.

Thong, J., \& Yap, C. (1995). CEO characteristics, organizational characteristics, and information technology adoption in small businesses. International Journal of Management Science, 23, 429-442. http://dx.doi.org/10.1016/0305-0483(95)00017-I

Tsamenyi, B., Onumah, J., \& Tetteh-Kumah, E. (2010). Post-Privatization Performance and organizational change: Case studies from Ghana. Critical Perspectives on Accounting, 21, 428-442. http://dx.doi.org/10.1016/j.cpa.2008.01.002

Vo, T., \& Nguyen, D. (2011). Corporate ownership structure and organizational structure in a transition economy: The case of Vietnam. International Journal of Economics and Finance, 3, 36-47. http://dx.doi.org/10.5539/ijef.v3n4p36

Wang, Y. (2011). Isomorphic relationship between regional culture and organizational culture: A case study of Daqing Oilfield Limited Company. Proceedings of the International conference on Management Science and Industrial Engineering (MSIE) (pp. 56-69). Harbin: China. (January 8-11) 
Wilderom, C., Glunk, U., \& Maslowski, R. (2000). Organizational culture as a predictor of organizational performance. In N. Ashkanasy, C. Wilderom, \& M. Peterson (Eds.), Handbook of Organizational Culture and Climate. (pp. 193-209). Sage Publications, Inc.

\section{Copyrights}

Copyright for this article is retained by the author(s), with first publication rights granted to the journal.

This is an open-access article distributed under the terms and conditions of the Creative Commons Attribution license (http://creativecommons.org/licenses/by/3.0/). 